\title{
Study on research-oriented teaching model of "oil and gas development database and its application"
}

\author{
Jianguo Wang \\ Petroleum engineering department \\ China University of Petroleum \\ Beijing, China \\ E-mail: wjglww@yahoo.com.cn
}

\author{
Long Chen \\ Petroleum engineering department \\ China University of Petroleum \\ Beijing, China \\ E-mail: \\ iamdennisyoung2007@163.com
}

\author{
Fengrui Yu \\ Lvbiao Center School \\ Shandong, China \\ E-mail: 18264617179@163.com
}

\begin{abstract}
Recently, in the context of education reform in the national higher education institution, China University of Petroleum, Beijing Campus (CUP), starts the course reformation of "oil and gas development database and its application". In correlation with present problems such as unspecific teaching contents, no change in teaching methods and limited evaluation mode, we positively research teaching methods and means for this course. In order to give a better understanding of this course for different majors, we mix the knowledge about Metadata and Data Model with the course content. Regarding to the teaching methods, we add the group practice section, database design competition and literature research for special subject so that we can train their research learning ability. Meanwhile, the traditional single test mode has also been transformed. To scientifically measure students' understanding of knowledge, we increase the weight of normal performance and practice section.
\end{abstract}

Keywords-Education reform; Oil and gas development; Database; Combination of theory and practice

\section{BACKGROUND OF PROJECT RESEARCH AND REFORM}

In recent years, we have achieved great development in our higher education and have initially realized the popularization of higher education. There are about 2000 colleges and universities of different types now and several million students graduating from these schools every year. However, since China is a large labour-surplus country, many students have unprecedented difficulties in applying for a post under contemporary employment situation, which, definitely, will hinder the positive development of our country's higher education ${ }^{[1]}$. So, in order to give students a better adaptation to the needs of current society, quite a lot of schools choose to set popular majors to cater to the market orientation or make efforts to cultivate the inter-disciplinary and adaptable talents in droves. It can be said that these measures all have achieved some success. But there are still some hidebound teaching methods which influence the improvement of students' practical and innovation capacity.

China University of Petroleum-Beijing launches the undergraduate teaching reform closely around the development positioning of "construction of world-class research university in petroleum and petrochemical fields" and the undergraduate talent cultivation mode of "Thick foundation, broad profession, Strong capacity, High quality". Our school focuses on training science and humanistic quality, innovation spirit and ability for the students and establishing the distinguishing innovative undergraduate talents cultivate system for research college.

In the context of the national and school-wide teaching reform, we start the reformation for the course of "oil and gas development database and its application". The database about oil and gas development is an important technique to improve oilfield development and management efficiency in an information era. This course will train students to be familiar with the basic structure and technique of oilfield database and to apply these technologies to production and scientific research.

Current teaching situation of "oil and gas development database and its application”:

\section{A. Unspecific teaching content.}

"Oil and gas development database and its application" is a basic course set up for the seniors majoring in petroleum engineering and computer engineering. As far as students majoring in petroleum engineering, the knowledge of database is their weak point. The students majoring in computer also are short of the knowledge about reservoir engineering. But current teaching still stays in the stage of unified course contents. The students of different levels and majors usually receive the same contents regardless of thinking about their professional characteristics. So on the one hand, the teacher cannot give attention to the two majors in this case; on the other hand, the teacher is difficult to perform the two majors' ability to solve pratical problems with what they have learned simultaneously.

\section{B. No change in the teaching methods.}

This is a course combined petroleum engineering and computer engineering. As for teaching methods, the teacher still continues using the form that teacher gives explanations to the points or shows with the PPT and students are listening to them. The existence of multimedia tools just reduces the workload of teacher and increases the amount of information. There is no help for the students' mastery of knowledge. Because of such a large amount of contents, students find it hard to grasp the main 
point and to write a practical oilfield development program personally.

\section{Limited evaluation mode.}

Presently, most courses of our school still evaluate students by their mid-term and final grades. This evaluation mode doesn't get out of the traditional examoriented education. Students always struggle for the scores so that it is hard to improve their enthusiasm to acquire knowledge. As a result, they lack strong analytical and problem-solving skills and their understanding of basic concepts still remains at the theoretical level. They, consequently, have a poor capability of practice and limited innovation consciousness and capability.

\section{THOUGHTS AND METHODS OF REFORM}

With the aim of cultivating self-learning ability, logical ability, implementing ability and innovation ability for the students, we actively carry out the reformation of teaching methods and means.

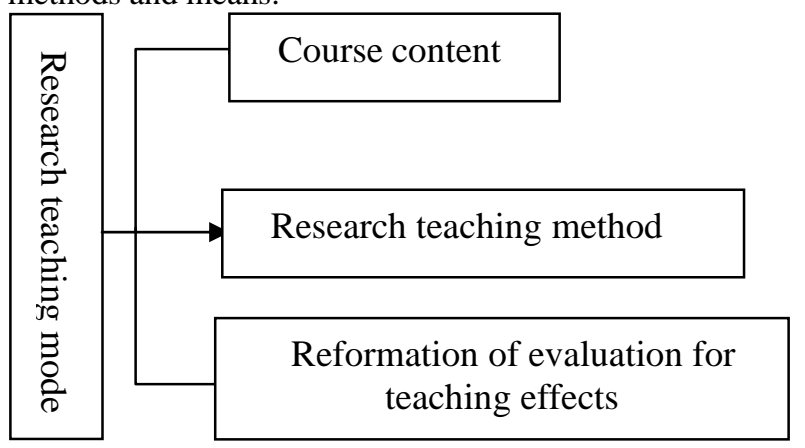

III. THE STATUS OF RESEARCH AND REFORMATION FOR THIS PROJECT

\section{A. Reformation and innovation of teaching content}

Contemporary science and technology presents a well differentiated and integrated trend and the theory of higher education recently also develops in these two tendencie ${ }^{\mathrm{s}[3]}$ : The first one is an unceasing differentiation of disciplines. When the new knowledge continuously accumulates to that it can theoretically innovate around a specific phenomenon and its results can construct a system, a new subdiscipline is born. The second one is a continuous integration of different disciplines. This is because we must use theory and method from different disciplines when solving the practical problems encountered by the higher education reform. And these multiple-discipline crossing lay a good foundation for the birth of new knowledge. This newly-formatted knowledge usually shows a comprehensive characteristic. Once it accumulates to construct a new system, an integrated discipline is also born ${ }^{[4]}$. These two methods are two main routes of theoretical innovation for higher education contemporarily.

The teaching content innovation of "oil and gas development database and its application" reflects in the crossing and integrating of two disciplines. This course is an optional course providing for the seniors majoring in petroleum engineering and computer engineering. The two majors have learned large amount of their own major knowledge, but there is no intersection between each other. According to this situation, I intend to add the content of oilfield-development-related technical introduction so that the students majoring in computer engineering can rapidly understand contents of petroleum. For the contents of database technology principles and Oracle, students studying petroleum know little about them. So I especially add some introduction about metadata, data item structure, table structure and data structure which covers the knowledge about both disciplines. This part of teaching content is the foundation of oilfield database design and also gives a better understanding of this course for both majors. The integration of these knowledge makes this course more comprehensive and diverse, thus it has the value of practical application. Besides, both majors master their own knowledge and broaden their scope of knowledge at the same time, which lay a theoretical foundation for further oilfield development work.

\section{B. Change in the way of teaching}

"Oil and gas development database and its application" is an optional course which combines petroleum engineering and computer engineering. According to the situation that most of students have mastered one or more programming language or database language before they learn this course, the students are proportionally divided into five groups and every group is given different raw data about practical oilfield development including production data of oil and water well, production data of gas well and analytical data ${ }^{[5]}$. Everyone of each team are supposed to work together to decide the basic content of oilfield development database, such as data dictionary and data structure, without any restriction to the database language and programming language. Some simple functions such as data query, insert, delete and edit are finished by the data language learned by the computer majoring students. On the basis of this oilfield develop database, related images which are used to dynamic analysis are showed in a view form. According to the diversity of dynamic analysis images at different time, students majoring in petroleum engineering are asked to expound the dynamic characteristics and put forward the corresponding engineering adjustment measure. The one who should report the results and explain the source program is decided by his team member. The scores of each team member are also given by the students themselves.

\section{Add section of literature research for special subject and cultivate inquiry learning capacity}

Practice section is a very significant part in the teaching content. In order to achieve the desired teaching targets and reverse the situation that teacher gives explanations to the points and the students are just listening to teachers' talk, we must combine practice section with theory teaching closely. Database design 
competition section and literature research for special subject section are the most direct embodiment of practice teaching ${ }^{[6]}$, through which we can lead and train students to flexibly master the theory and apply it to practical work.

Oil field develop database is a subsystem which belongs to the digital oilfield ${ }^{[7]}$. With the aim of giving students an overall understanding of oilfield develop database and some related key technology, such as geographic information system; database system and dynamic analysis technology, students can choose any special subject to start their research and write literature review. Through this way, their ability of research and speculative study can be trained.

When we carry on a reform of higher education, the most important thing in epistemology is that we must balance the relationship between theory and practice ${ }^{[9]}$. The practice is the source of theory. At the same time, practice is the sole criterion for testing truth and is the precondition of improvement for the theory. Meanwhile, theory can develop to beyond practice as a relatively independent ideology so that it can play guidance and forecast function over practice. So the relationship between each other is dynamic and dialectical ${ }^{[10]}$. The purpose of adding practice section to this course is to improve students' ability of self-study and develop their habit of research study, which is good for promoting them to digest the theory knowledge learned in the class and apply these theories to practice.

\section{Change of assessment methods}

We transform the traditional single examination method into a new assessment method which combines "normal performance" including course project and question answering, "practice section" including database design competition and literature research, "final exam". We decrease the weight of final exam and increase that of normal performance and practice section, while the normal performance accounts for 30\%, practice section 30\% and final exam $40 \%$. It favors for students to pay more attention to peacetime performance in class and strengthen their ability of practice. Due to the practicality and technicality of this course, the assessment method should be divided into two parts, which means that the assessment of practice ability and theory knowledge. The former one focuses on assessing students' problems-solving capacity and innovative thinking capacity. And the latter one focuses on assessing the familiarity and comprehension of key concept and principle. However, traditional method, close-book exam, just focuses on testing students' knowledge hierarchies, which will falsely lead them to learn by rote for the scores ${ }^{[11]}$. The traditional method will do harm to their all-round development and also don't meet the requirements of scientific methodology.

We are supposed to innovate in methodology if we want to make a reform of higher education. The innovation of methodology mainly means the innovation of thinking mode, and this innovation is an important prerequisite for theory innovation about higher education ${ }^{[12]}$. A backward and unscientific thinking manner will hinder the further development of theory; on the contrary, a progressive and scientific one will promote its deep-level development. The traditional thinking mode considers that students who score high in the final exam are the ones who study well, which is no longer regarded as a scientific assessment method ${ }^{[13]}$. The reformation of assessment will give a more comprehensive evaluation of the students' study condition, which is another innovation in methodology.

\section{FURTHER STUDY ON THE REFORM IDEAS}

(1) For the content of database technology principle, we are going to increase the time of practice on computer. As to the type of database, students can make a free choice.

(2) For the part of database, we want to further strengthen the content of metadata, data items structure and data structure. Because this part can provide the opportunities for the students majoring in petroleum engineering to give a full play to their professional knowledge and is also the areas for further study when combining the content of database.

(3) Since the construction of digital oilfield advances quickly in most oilfields, the construction of main database for oil-gas exploration and exploitation has been accomplished ${ }^{[14]}$. For the both majors who are going to find their jobs, there are more opportunities to develop a database for a special subject on the basis of such a main database. So the oil-gas develop data design should strengthen the content about the construction and application of a database for a special subject so that students can learn to meet practical needs.

(4) The choice of classroom should be determined by the number of final enrollments. Small number of enrollments is favorable for realizing small class teaching and for implement of research-centered and interactive teaching. If the classroom is too big, the effect of researchcentered teaching will be influenced.

\section{CONCLUSION}

“Oil and gas development database and its application” is a very significant optional course set up for the seniors majoring in petroleum and computer engineering. What we have discussed above is just some elementary reform measures against the problem emerging in the teaching of this course. Since the oilfield development technology constantly moves forward and the knowledge also continuously updates, the teaching methods which seem good now may appear out of date in a time. Teachers should continuously study and keep pace with the times so that we don't fall behind and can develop qualified graduates for the future oil industry of our motherland.

\section{REFERENCES}

[1] K. R. Howe. Two dogmas of educational research. Educational Researcher, Vol. 14. No.8. 1985.

[2] Brown, A. L. 1992. Design experiments: theoretical and methodological challenges in creating complex interventions in classroom settings. The journal of the learning sciences (Hillsdale, NJ), vol. 2, p. 141-178. 
[3] T. Husen, et al. The International Encyclopedia of Education. Vol.4. Oxford: Pergamon Press. 1985. P. 2216.

[4] cf. P. L. Dressel and L. B. Mayhew. Higher Education as a Field of Study: the Emergence of a Profession. San Francisoc: Jossey-Bass, Publishers. 1974.

[5] R. R. Sherman and R. B. Webb (eds.). Qualitative Research in Education: Focus and Methods. New York: The Falmer Press. 1988.

[6] Ted Moon. Digital oilfield developments addressed in joint workshop. SPE.2009.9.

[7] Boakari, F.M. Educational system reform as legitimation for continuity: the case of Brazil. In: Rust, V.D. (Ed.), International Perspectives on Education and Society. JAI Press, Greenwich, CT.

[8] Altbach, P.G. and Peterson, P.M. (eds.) (1999). Higher Education in the 21st Century: Global Challenge and National Response. Institute of International Education and Boston College Centre for International Higher Education.

[9] Zhou, Z. (1997). 'Australian institutional amalgamations and their implications for China', Researches in Higher Education of Engineering 3, 59-62 (in Chinese).

[10] Bai, L. M. (1998). 'The metamorphosis of China's higher education in the 1990s', in Sullivan, K. (ed.), Education and Change in the Pacific Rim: Meeting the Challenges. Oxfordshire: Triangle Journal Ltd., pp. 241-265.

[11] China Education Yearbook 2000-2010 (2010). Beijing: The Encyclopaedia of China Publishing House (in Chinese).

[12] Ding, G. (1996). Reform and Action Suggestions of China's Higher Education: The World Bank Report. Shanghai Higher Education Research, no. 1, 23-26 (in Chinese).

[13] Erik De Corte, Lieven Verschaffel. High-powered Learning Communities: Design Experiments as a Lever to Bridge the Theory/Practice Divide. Prospects, Vol. XXXII, no. 4, December 2002.

[14] E. Tempelman A. Pilot. Strengthening the link between theory and practice in teaching design engineering: an empirical study on a new approach. Int J Technol Des Educ (2001) 21: 261-275. 